\title{
USE OF FINELY GROUND RECYCLED CONCRETE FOR IMPROVEMENT OF INTERFACIAL ADHESION IN FIBER-REINFORCED CEMENTITIOUS COMPOSITES
}

\author{
RADIM HLŮŽEK*, JAN TREJBAL \\ Czech Technical University in Prague, Faculty of Civil Engineering, Thákurova 7, 166 29 Prague, \\ Czech Republic \\ * corresponding author: radim.hluzek@fsv.cvut.cz
}

\begin{abstract}
This paper deals with an improvement and an assessment of a polymeric macro-fibers adhesion to the cement matrix. For this purpose, two approaches were employed - (i) roughening of fibers using a plasma treatment and (ii) an addition of finely ground recycled concrete (amount 30 wt. \%) to the matrix ensuring the roughness of interfacial zones. Polyethylene terephthalate (PET) and polypropylene (PP) fibers, both ca. $0.3 \mathrm{~mm}$ in a diameter, were used. These were surface roughened using a cold oxygen plasma treatment and then observed by means of the scanning electron microscopy. Consequently, pull-out tests of an individual fiber embedded $25 \mathrm{~mm}$ in the matrix were performed, while the force needed for fiber pullout was recorded. Results have shown that plasma treated fibers reached on a better adhesion with the matrix by up to ca. $5 \%(\mathrm{PET})$ and $20 \%(\mathrm{PP})$, if compared to reference fibers. When recycled concrete was used, the adhesion increased further by about 5-10\% for both fiber types.
\end{abstract}

KEYWORDS: Recycled concrete, waste, adhesion, fiber reinforcement, fibrous composite.

\section{INTRODUCTION}

It is widely known that waste production shows an unsustainable trend in global scale. This also hold true for the construction industry. It is reported that global production of construction demolition waste ranges from 3 to 10 billion tonnes per year of which 3.5 million tonnes in the Czech Republic. These basic data provide the sufficient proof of why it is necessary to deal with the reduction of waste and its re-use. Therefore, a law on a total ban on landfilling of inert waste with effect from 2024 was ready within the European Union [1]. It is therefore necessary to find new efficient solutions for the reprocessing of construction waste including concrete from demolished buildings [2].

In civil engineering praxis, waste concrete is crushed and aggregate is then separated and re-used within production of new concrete mixtures. But the question of the use of dust emerging during crushing and grinding processes arises [3]. Such dust may contain up to $10 \%$ of un-hydrated cement grains [4]. These can be exposed and isolated from dust using a highspeed milling [5]. It is possible to use such obtained material as replacement of cement at the form of socalled active micro aggregate. It is appropriate for production of lightweight concrete blocks, mortars, etc. [4 6]. However, the potential of this material is still limited due to particles different thickness and size and presence of various impurities [4, 7, 8.

Some researches tried to use finely ground recycled concrete for filling of pores in various cement-based composites. Individual particles can fill also spaces in interfacial zones in fibrous composite materials and thus contribute to the better adhesion between reinforcing fibers and the matrix [9, 10. Unfortunately, such phenomenon has not been so far clearly explained, tested and described. Therefore, we tested the adhesion between smooth and roughened fibers and the cement matrix containing finely ground recycled concrete by means of pull out tests of individual fibers from specimens made from both matrices.

\section{MATERIALS}

\subsection{FIBERS}

Two types of polymeric macro-fibers were used: (i) polyethylene terephthalate (PET) and (ii) polypropylene (PP). These were made by the Czech manufacturer Spokar $(\mathrm{Plc})$. Both types were surface treated using cold oxygen plasma to roughen and to activate their surface. This process has been described in more details in our previous study 11. Fibers are further marked as follows: PP and PET, reference; PP-T and PET-T, treated. The basic geometric and mechanical properties of fibers are summarized in Table 1 .

\subsection{Cement And Finely GROUND RECyCled CONCRETE}

Two different types of matrices were made. The first one was composed only from Portland cement (CEM I $42.5 \mathrm{R}$ ) with water to cement ratio (w/c) equal to 0.4 (marked CEM), while the second one contained finely ground recycled concrete in amount of $30 \%$ of weight of cement (marked REC), water to binder 


\begin{tabular}{ccccc}
\hline Fiber type & $\begin{array}{c}\text { Diameter } \\
{[\mathbf{\mu m}]}\end{array}$ & $\begin{array}{c}\text { Density } \\
{\left[\mathbf{k g} / \mathbf{m}^{3}\right]}\end{array}$ & $\begin{array}{c}\text { Young's modulus } \\
\text { of elasticity }[\mathbf{G P a}]\end{array}$ & $\begin{array}{c}\text { Tensile strength } \\
{[\mathbf{M P a}]}\end{array}$ \\
\hline PET / PET-T & 335 & 950 & 5.8 & 238 \\
PP / PP-T & 305 & 900 & 6.1 & 440 \\
\hline
\end{tabular}

TABLE 1. Basic geometric and mechanical properties of fibers 12 .

$(\mathrm{w} / \mathrm{b}=\mathrm{w} /(\mathrm{CEM}+\mathrm{REC}))$ was increased to 0.41 (increased due to the high specific surface area of recycled concrete). Waste recycled concrete used in this study, originated from railway sleepers, was ground using high-speed milling technology with maximum grain size of $0.25 \mathrm{~mm}$. The hardening and curing of all test produced specimens took place in standard laboratory conditions for 28 days.

\section{Experimental Methods}

\subsection{SCANNING ELECTRON MiCROSCOPY}

Morphology of fibers was observed using the Merlin Zeiss scanning electron microscopy device. In order to perform this analysis, it was necessary to provide sufficient electrical conductivity of the fiber surface. Therefore, all tested fibers were coated by a thin layer of gold using the BOC Edward Scancoats Six machine. Process parameters were: $1.3 \mathrm{kV}$ voltage, $35 \mathrm{~mA}$ electric current, and $40 \mathrm{~s}$ plating time. It was assumed that such a treatment had not any effect on physical properties of fiber surfaces.

\subsection{Pull-out tests}

Prismatic samples having dimensions of $25 \times 20 \times 25 \mathrm{~mm}$ were made from both types of matrices. The single fiber was always placed in the center of the specimen with a embedded length equal to the prism height, i.e. $25 \mathrm{~mm}$. An illustrative specimen is shown in Figure 1. Pull-out tests were performed 28 days after hardening and curing of mixtures. In the first place, each tested sample was clamped into the static jaw of the hydraulic loading frame (Web Tiv Ravestein FP100). Secondly, the free end of the fiber was clamped into the opposite sliding jaw of the press. Finally, the fiber was gradually pulled out from the sample at a constant rate of $2 \mathrm{~mm} / \mathrm{min}$. During the process, the free-end displacement and resisting force were measured. The loading process was terminated when the displacement reached $5 \mathrm{~mm}$. Such obtained data were evaluated using the DiPro software based on the MatLab software. The adhesion between the two materials was then expressed by interfacial shear stress (1) and (2), which is commonly used in the field of fiber reinforced composites because it provides values normalized to the fiber surface area. The stress was calculated in two stages: after reaching a fiber free-end pull out of $3.5 \mathrm{~mm}$ (hereinafter referred to as "3.5") and when the measured force achieved on its maximum (denoted by the "MAX" index).

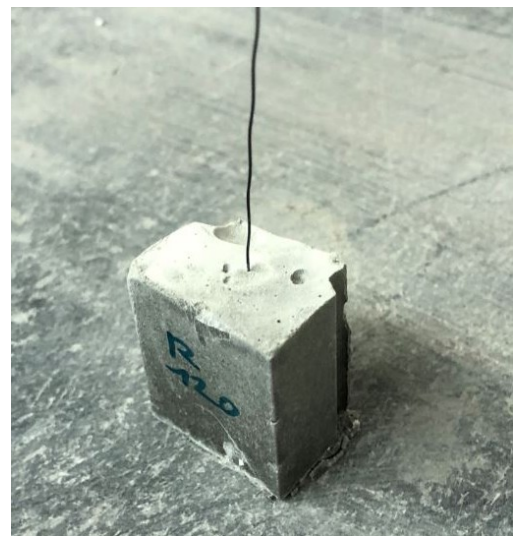

Figure 1. Prepared specimen for the pull-out test.

$$
\begin{gathered}
\tau_{\max }=\frac{F_{\max }}{C_{f} l_{e}} \\
\tau_{3.5}=\frac{F_{3.5}}{C_{f} l_{e}}
\end{gathered}
$$

$F_{3.5}$ and $F_{\text {max }}$ represent the force necessary to reach the $3.5 \mathrm{~mm}$ fibers free-end displacement and the maximal reached force, respectively. $C_{f}$ is a fiber circumference and $l_{e}$ is the embedded fiber length.

\section{RESUlts}

\subsection{SCANNING ELECTRON MiCROSCOPY}

A scanning electron microscopy image of the reference PET fiber (Figure 2) revealed its smooth surface, which is very inappropriate from the mechanical point of view. Compared to that, the same fiber after 120 seconds of the plasma treatment was already gently roughened by irregular holes, as shown in Figure 2 . This desirable morphology change was caused by surface etching and the ion bombardment. It should be noted that the roughening of the treated fibers surface was observed only after 120 seconds. If the fibers were exposed to plasma for shorten time, there were no visible changes on their surface.

Similarly to PET fibers, the surface of reference PP fibers was too smooth, except for longitudinal profiling apparently originates from production technology (stretching process), as shown in Figure 3. After 120 seconds lasting modification, minor changes - longitudinal recesses along the length of the fiber in morphology were observed, see Figure 3. It can be 
assumed that these tiny morphology changes will not affect the adhesion of fibers to the matrix. Extending the exposure time would certainly increase the effect of roughening, but cross-section of fibers significantly decreases.

\subsection{Pull-out tests}

Based on pull-out test results, it can be observed that the highest value of the interfacial shear stress was recorded in the case of plasma modified PP fibers in combination with the matrix containing finely ground recycled concrete (REC). As shown in Figure 5, the interfacial shear stress at maximum force was about $0.45 \mathrm{MPa}$ and $0.38 \mathrm{MPa}$ at the $3.5 \mathrm{~mm}$ fibers free-end displacement, respectively. In the case of cementitious matrix with same fibers, results were as follows: ca. 0.4 resp. 0.34 MPa. Furthermore, it should be noted that for untreated fibers, values of the interfacial shear stress with respect to the matrix used did not differ substantially.

In the case of PET fibers, the same trend as for PP fibers mentioned above can be observed, but only with significantly smaller differences, see Figure 4 Unlike the assumption, it has been found that the adhesion between reference PET fibers in combination with the matrix containing recyclate (REC) was a little bit worse than between same fibers and the matrix containing only cement (CEM). The maximum interfacial shear stress dropped from ca. 0.31 MPa (CEM) to $0.28 \mathrm{MPa}$ (REC) and at the $3.5 \mathrm{~mm}$ displacement from 0.31 to $0.3 \mathrm{MPa}$. Nevertheless, in the case of the use of plasma treated fibers, the adhesion was increased, especially in combination with the matrix containing recycled concrete. The maximum shear stress was increased by ca. $5-10 \%$ up to ca. $0.33 \mathrm{MPa}$.

To sum up, it can be stated that the use of finely ground recycled concrete as a partial cement additive can improve the adhesion between polymeric fibers and the cement-based matrix, but only in the case of the use of plasma treated fibers. In the case of reference fibers with a smooth surface, the use of recycled material appears to be ineffective. Thus, physical interaction between fine particles of the recycled material and the plasma-roughened fiber surface plays a significant role in achieving the desired increase in the adhesion between the fiber and the matrix.

\section{Conclusion}

This study researched the adhesion between polymeric macro fibers (polyethylene terephthalate and polypropylene), having ca. $0.3 \mathrm{~mm}$ in the diameter, and two types of cement matrices. The reference matrix was composed of cement (CEM I $42.5 \mathrm{R}$, w/c 0.4 ), while in the second case, 30 wt. $\%$ of cement was replaced with recycled concrete at the form of finely ground powder. In order to roughen fiber surfaces and thus to ensure the adhesion between them and the matrix, fibers were treated by cold oxygen plasma. Changes on fiber surfaces were observed using the
SEM microscopy. Interaction between the two materials was assessed directly by means of the single fiber pull-out test from matrix specimens $(25 \times 20 \times 25 \mathrm{~mm})$. It was shown that the surface roughening of PP fibers was much more intensive than in case of PET fibers. Pull-out tests revealed that the adhesion between PP and PET fibers and the cement matrix was constant regardless to the fiber treatment. Similarly, when these fibers were pulled out from the matrix containing finely ground concrete powder, the adhesion was not increased, if compared to reference materials. On the other hand, treated fibers (both PP and PET) showed significantly increased adhesion with the matrix containing recycled concrete. This phenomenon was attributed to fiber roughening and to working of recycled concrete grains in interfacial zones.

\section{ACKNOWLEDGEMENTS}

This work was financially supported by the Czech Technical University in Prague - SGS project SGS18/037/OHK1/1T/11 and the Czech Science Foundation [grant number GA ČR 17-06771S]. The authors would also like to thank to Tereza Horová for her help with this research.

\section{REFERENCES}

[1] M. Škopán. Analysis of the current state of c\&dw recycling in the czech republic and assessment of development options. Recycling 129(9):19-27, 2005.

[2] M. D. Schepper, R. Snellings, K. D. Buysser, et al. The hydration of cement regenerated from completely recyclable concrete. Construction and Building Materials 60:33-41, 2014. DOI:10.1016/j.conbuildmat.2014.02.067.

[3] T. Pavlů, M. Šefflová. Environmental assessement of the structural elements with recycled aggregate. Recycling 129(5):108-112, 2005.

[4] J. Xiao, J. Li, C. Zhang. Mechanical properties of recycled aggregate concrete under uniaxial loading. Cement and Concrete Research 35(6):1187-1194, 2005. DOI:10.1016/j.cemconres.2004.09.020.

[5] L. Evangelista, J. de Brito. Mechanical behaviour of concrete made with fine recycled concrete aggregates. Cement and Concrete Composites 29(5):397-401, 2007. DOI:10.1016/j.cemconcomp.2006.12.004

[6] J. Topič, J. Trejbal, T. Plachý, Z. Prošek.

Relationship between compressive strength and young's modulus of cement paste with recycled concrete powder. Key Eng Mater 722 KEM:254-259, 2017. DOI:10.4028/www.scientific.net/KEM.722.254.

[7] V. Růžička. Lightweight blocks based on recycled concrete. Ph.D. thesis, Czech Technical University in Prague, Faculty of Civil Engineering, 2017.

[8] M. Etxeberria, E. Vázquez, A. Marí, M. Barra. Influence of amount of recycled coarse aggregates and production process on properties of recycled aggregate concrete. Cement and Concrete Research 37(5):735-742, 2007. DOI:10.1016/j.cemconres.2007.02.002 

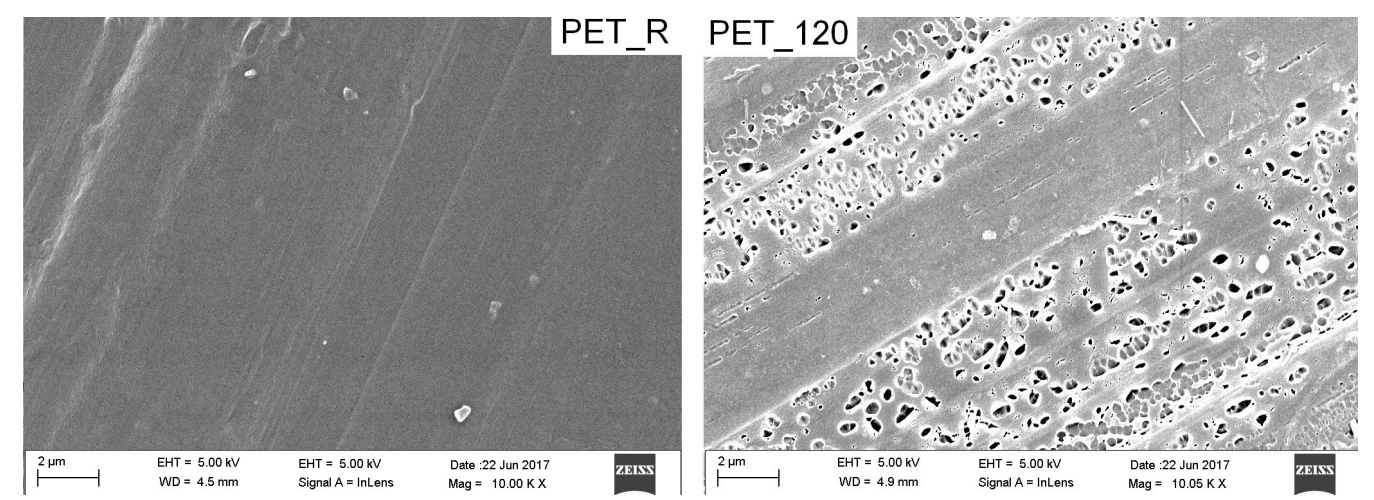

FIgURE 2. SEM images of reference (left) and modified (right) PET fiber.
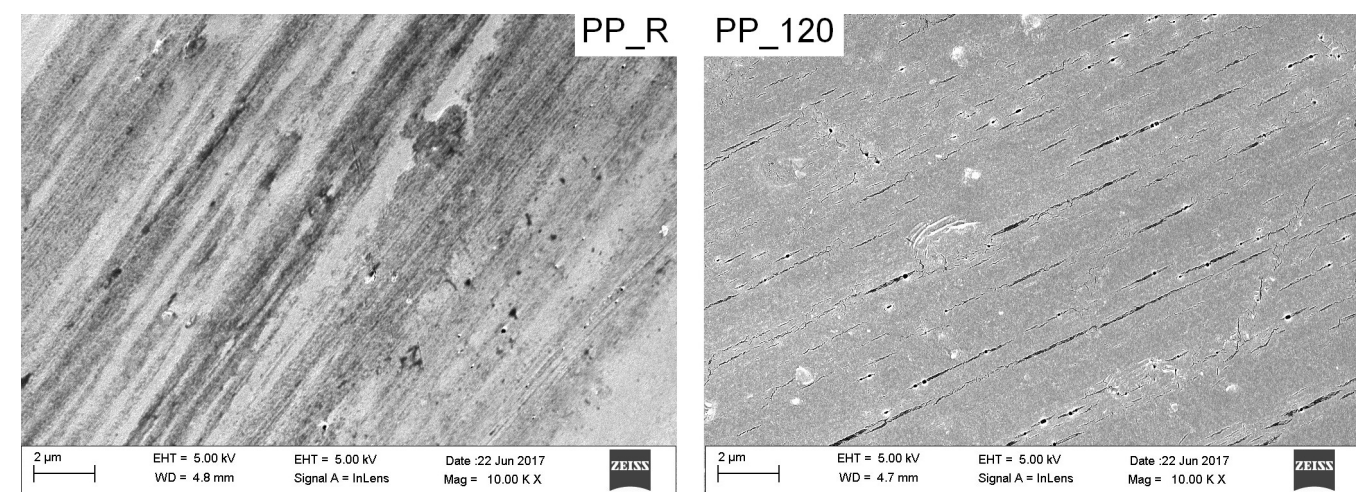

FiguRE 3. SEM images of reference (left) and modified (right) PP fiber.

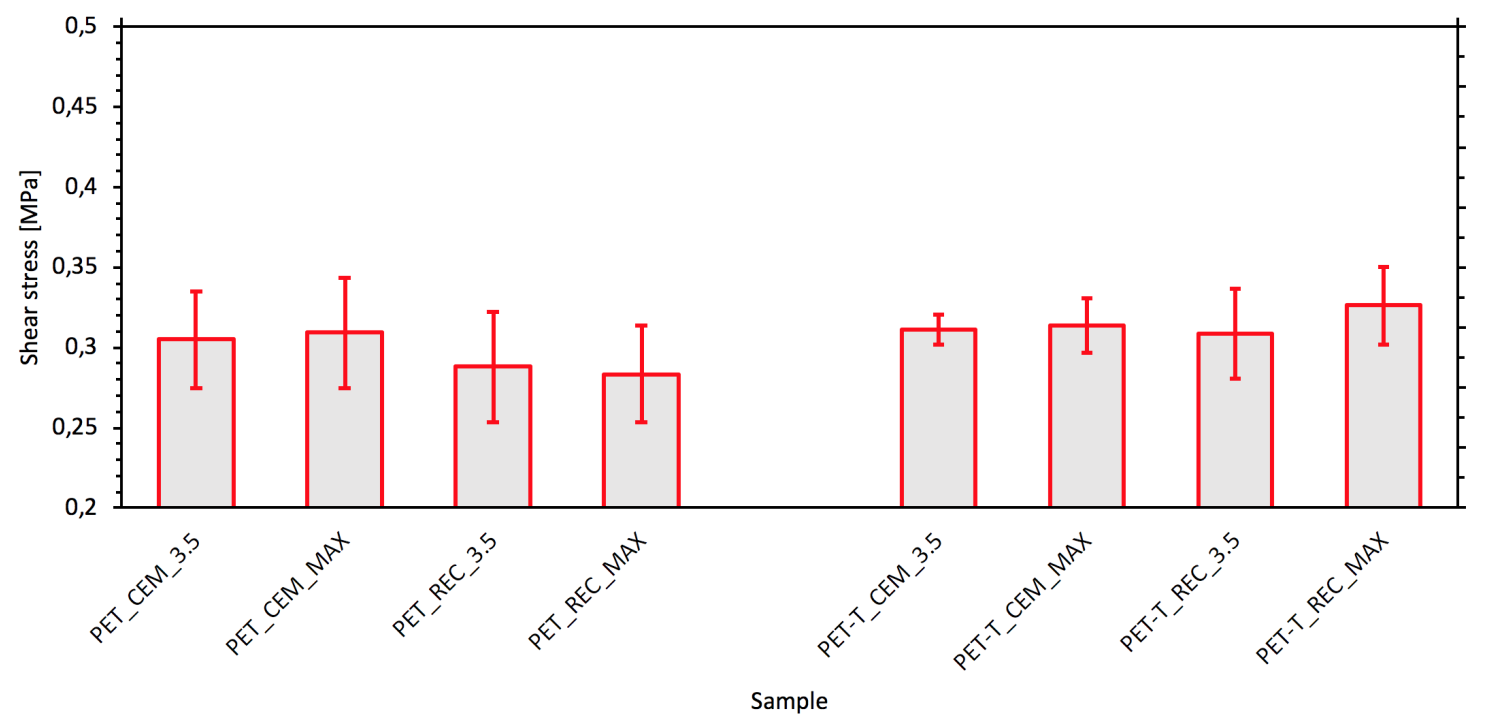

FIGURE 4. Interfacial shear stress values for different combinations of matrices and PET fibers calculated from the pull-out test. 


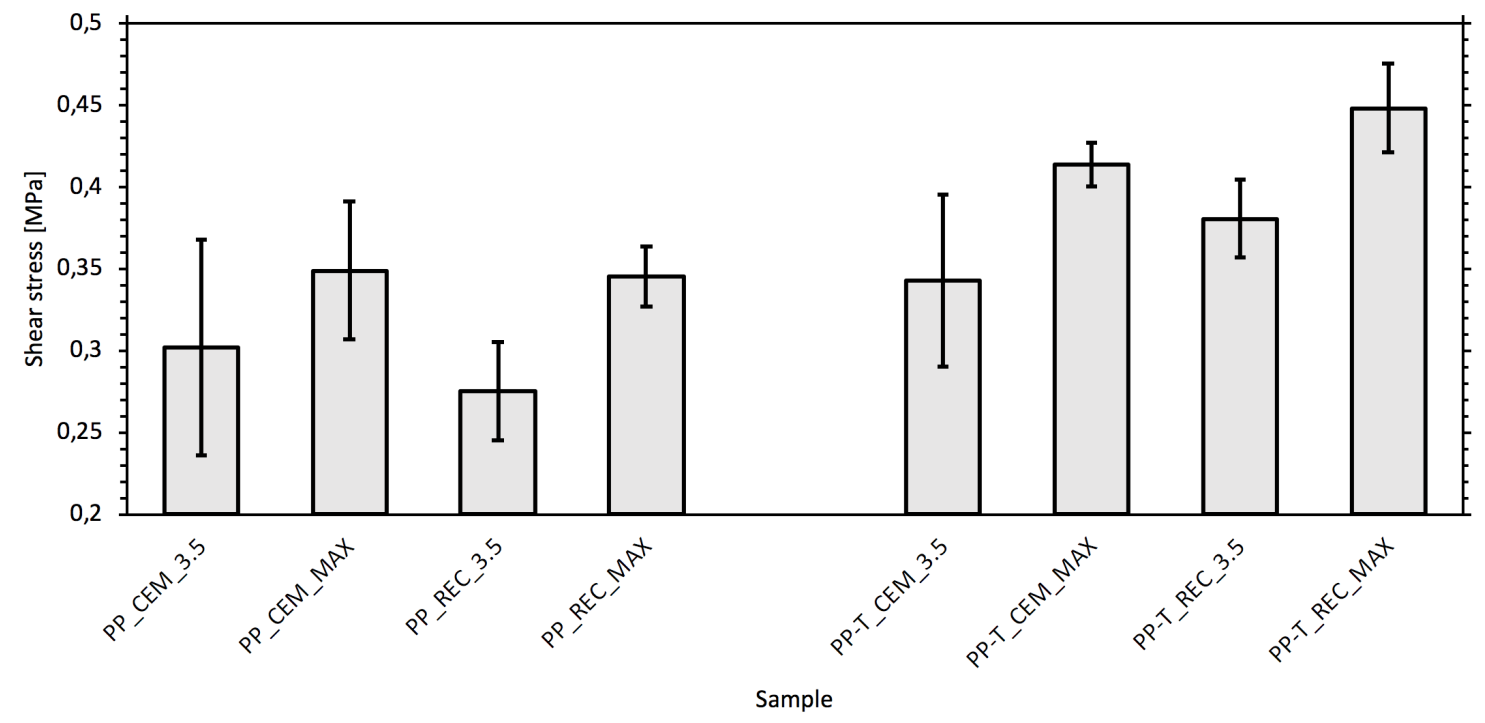

FiguRE 5. Interfacial shear stress values for different combinations of matrices and PP fibers calculated from the pull-out test.

[9] N. Sebaibi, M. Benzerzour, N. E. Abriak, C. Binetruy. Mechanical properties of concrete-reinforced fibres and powders with crushed thermoset composites: The influence of fibre/matrix interaction. Construction and Building Materials 29:332-338, 2012. DOI:10.1016/j.conbuildmat.2011.10.026

[10] K. R. Akça, Ö. Çakır, M. İpek. Properties of polypropylene fiber reinforced concrete using recycled aggregates. Construction and Building Materials 98:620630, 2015. DOI:10.1016/j.conbuildmat.2015.08.133.
[11] R. Hlůžek, Z. Prošek, J. Trejbal, et al. Plasma treatment impact on physical and chemical properties of polymeric fibers. Acta Polytechnica CTU Proceedings 13:49-54, 2017. DOI:10.14311/app.2017.13.0049

[12] R. Hlůžek. Analysis and modification of interfacial zones between cementitious matrix and fiber reinforcement. Ph.D. thesis, Czech Technical University in Prague, Faculty of Civil Engineering, 2018. 